\title{
Precise Point Positioning using Triple-Frequency GPS Measurements
}

\author{
Mohamed Elsobeiey \\ (Department of Hydrographic Surveying, Faculty of Maritime Studies, King Abdulaziz \\ University, Kingdom of Saudi Arabia) \\ (E-mail: melsobeiey@kau.edu.sa)
}

\begin{abstract}
Precise Point Positioning (PPP) performance is improving under the ongoing Global Positioning System (GPS) modernisation program. The availability of the third frequency, L5, enables triple-frequency combinations. However, to utilise the modernised L5 signal along with the existing GPS signals, P1-C5 differential code bias must be determined. In this paper, the global network of Multi-Global Navigation Satellite System Experiment (MGEX) stations was used to estimate P1-C5 satellites differential code biases $\left(D C B_{P 1-C 5}^{S}\right)$. Mathematical background for triple-frequency linear combinations was provided along with the resultant noise and ionosphere amplification factors. Nine triple-frequency linear combinations were chosen, based on different criteria, for processing the modernised L5 signal along with the legacy GPS signals. Finally, test results using real GPS data from ten MGEX stations were provided showing the benefits of the availability of the third frequency on PPP solution convergence time and the precision of the estimated parameters. It was shown that triple-frequency combinations could improve the PPP convergence time and the precision of the estimated parameters by about $10 \%$. These results are considered promising for using the modernised GPS signals for precise positioning applications especially when the fully modernised GPS constellation is available.
\end{abstract}

\section{KEY WORDS}
1. Precise Point Positioning.
2. GPS Modernisation.
3. Hardware Delay.

Submitted: 12 December 2013. Accepted: 3 November 2014. First published online: 25 November 2014.

1. INTRODUCTION. Termination of Selective Availability (SA) was the first step in the GPS modernisation program. The first satellite of the modernised Block IIR-M series was launched on 25 September 2005. Block IIR-M transmits a new civil L2C code on the L2 frequency in addition to the new military M-code on L1 and L2. The subsequent generation after Block IIR-M was Block IIF. The main feature of the Block IIF generation is the addition of a third civil signal denoted as L5 as well as two military M-code signals on a new frequency of $1176 \cdot 45 \mathrm{MHz}$ (L5) (Hofmann-Wellenhof et al., 2008). In addition, the GPS modernisation program includes the launch of Block III satellites, which will transmit the modernised civil L1C signal in addition to the C/A-code. In September 2013 the GPS constellation consisted of 31 satellites, including seven Block IIR-M satellites and four Block IIF satellites (USNO, 2013). 
Generally, modernised GPS signals have better performance than legacy signals. The Block IIR-M L2 signal provides greater signal power to the user. L-band power is increased on both L1 and L2 frequencies, especially at low elevation angles (Elsobeiey and El-Rabbany, 2013). Block IIF satellites, on the other hand, broadcast the new modernised L 5 signal. The L5 civil signal has been designed to meet safety-of-life applications requirements (Hofmann-Wellenhof et al., 2008). The L5 ranging codes have better autoand cross-correlation properties because they are ten times longer than the legacy C/A-code. An additional advantage is the higher power level of the L5 signal compared with other signals (Elsobeiey and El-Rabbany, 2013). In addition to the higher power, the L5 ranging codes provide better interference, multipath and noise.

The availability of a third frequency is expected to affect the PPP performance especially as it has the highest power level and is less affected by multipath and noise. Great efforts have been made to investigate several optimum multi-frequency combination observables using different criteria such as reducing the ionospheric effect and providing long wavelength.

Triple-frequency methods can be used to correct the ionospheric refraction at millimetre-level (Wang et al., 2005). In addition to ionospheric delay elimination, triplefrequency linear combinations can be used to mitigate the effects of thermal noise, tropospheric delay and multipath (Richert and El-Sheimy, 2007). However, limited numbers of triple-frequency combinations can provide wide lane wavelengths and retain the integer nature of carrier-phase ambiguities (Cocard et al., 2008). Ambiguity resolution in PPP using triple-frequency is much faster than that of dual frequency especially in a multipath environment (Geng and Bock, 2013). Melbourne-Wübbena linear combination of L2 and L5 observables can be used to perform extra-wide-lane ambiguity resolution. The resultant unambiguous carrierphase is then combined with L1 and L2 wide-lane carrier-phase to form an ionosphere-free observable with $3.4 \mathrm{~m}$ wavelength. However, the noise of this observable is 100 times the noise of the original carrier-phase (Geng and Bock, 2013).

All previous studies neglected the Differential Code Bias (DCB) which is very important in utilising the modernised C5 signal along with other GPS signals. In this paper, we used long GPS observation sessions to estimate P1-C5 differential hardware delays $\left(D C B_{P 1-C 5}^{S}\right)$ of the modernised GPS satellites broadcasting the modernised L5 signal. Mathematical background for triple-frequency linear combinations was provided along with the resultant noise and ionosphere amplification factors. Finally, GPS data from several MGEX stations was processed according to the selected triple-frequency linear combinations. The results showed that the triple-frequency PPP solution improved the positioning performance when compared with the traditional dual-frequency solution.

2. GPS OBSERVATION EQUATIONS. Typically, the International Global Navigation Satellite System (GNSS) Service (IGS) estimates its precise clock corrections using the ionosphere-free linear combination of P1 and P2 pseudoranges. By convention, hardware delays are ignored during the estimation process of the precise clock corrections. As such, an additional term to account for hardware delay should be applied when using IGS precise clocks. This additional term results from the combination of the neglected P1 and P2 hardware delays. As satellite hardware delay is different for each observable, this means that its absolute value cannot be determined 
Table 1. Satellite Differential Code Bias Corrections for Different Observables when using the IGS Satellite Clock Corrections.

\begin{tabular}{ll}
\hline Observable $(\mathrm{m})$ & Correction Term $(\mathrm{m})$ \\
\hline $\mathrm{C} 1$ & $+c D C B_{P 1-C 1}^{s}+\xi_{1} c D C B_{P 1-P 2}^{s}$ \\
$\mathrm{P} 1$ & $+\xi_{1} c D C B_{P 1-P 2}^{s}$ \\
P2 & $+\xi_{2} c D C B_{P 1-P 2}^{s}$ \\
$\mathrm{C} 5$ & $+c D C B_{P 1-C 5}^{s}+\xi_{1} c D C B_{P 1-P 2}^{s}$ \\
\hline
\end{tabular}

directly (Schaer, 1999). However, the difference between the hardware delays of two observables can be determined, and is known as Differential Code Bias, DCB. Table 1 summarises the hardware delay correction term required when using the IGS satellite clock corrections.

In Table 1, the following symbology is used:

$\left(C_{1}, P_{1}\right), P_{2}, C_{5}$ are pseudoranges on $\mathrm{L} 1, \mathrm{~L} 2$, and $\mathrm{L} 5$ frequencies, respectively $(\mathrm{m}), c$ is the speed of light in vacuum $(\mathrm{m} / \mathrm{s}), \xi_{1}$ equals $f_{2}^{2} /\left(f_{1}^{2}-f_{2}^{2}\right), \xi_{2}$ equals $f_{1}^{2} /\left(f_{1}^{2}-f_{2}^{2}\right)$, $D C B_{P 1-C 1}^{s}$ is the hardware delay difference of $\mathrm{P} 1$ and $\mathrm{C} 1$ observables (s), $D C B_{P 1-P 2}^{s}$ is the hardware delay difference of $\mathrm{P} 1$ and $\mathrm{P} 2$ observables (s) and $D C B_{P 1-C 5}^{S}$ is the hardware delay difference of P1 and C5 observables (s).

The mathematical models of GPS observables, code and carrier phase considering hardware delays and applying IGS satellite clock corrections, could be written as (Elsobeiey and El-Rabbany, 2013; Hofmann-Wellenhof et al., 2008; Leick, 2004):

$$
\begin{gathered}
C_{1}=\rho+c\left(d t^{r}-d t_{I G S}^{s}\right)+T+I_{1}+c d_{C 1}^{r}-c D C B_{P 1-C 1}^{s}-\xi_{1} c D C B_{P 1-P 2}^{s}+e_{C 1} \\
P_{1}=\rho+c\left(d t^{r}-d t_{I G S}^{s}\right)+T+I_{1}+c d_{P 1}^{r}-\xi_{1} c D C B_{P 1-P 2}^{s}+e_{P 1} \\
\Phi_{1}=\rho+c\left(d t^{r}-d t_{I G S}^{s}\right)+T-I_{1}+c\left(\delta_{\Phi 1}^{r}+\delta_{\Phi 1}^{s}-\xi_{1} d_{P 1}^{s}+\xi_{2} d_{P 2}^{s}\right)+\lambda_{1} N_{1}+\varepsilon_{\Phi 1} \\
P_{2}=\rho+c\left(d t^{r}-d t_{I G S}^{s}\right)+T+I_{2}+c d_{P 2}^{r}-\xi_{2} c D C B_{P 1-P 2}^{s}+e_{P 2} \\
\Phi_{2}=\rho+c\left(d t^{r}-d t_{I G S}^{s}\right)+T-I_{2}+c\left(\delta_{\Phi 2}^{r}+\delta_{\Phi 2}^{s}-\xi_{1} d_{P 1}^{s}+\xi_{2} d_{P 2}^{s}\right)+\lambda_{2} N_{2}+\varepsilon_{\Phi 2} \\
C_{5}=\rho+c\left(d t^{r}-d t_{I G S}^{s}\right)+T+I_{5}+c d_{C 5}^{r}-c D C B_{P 1-C 5}^{s}-\xi_{1} c D C B_{P 1-P 2}^{s}+e_{C 5} \\
\Phi_{5}=\rho+c\left(d t^{r}-d t_{I G S}^{s}\right)+T-I_{5}+c\left(\delta_{\Phi 5}^{r}+\delta_{\Phi 5}^{s}-\xi_{1} d_{P 1}^{s}+\xi_{2} d_{P 2}^{s}\right)+\lambda_{5} N_{5}+\varepsilon_{\Phi 5}
\end{gathered}
$$

where $\Phi_{1}, \Phi_{2}, \Phi_{5}$ are carrier-phase measurements on L1, L2, and L5, respectively (m), $\rho$ is the true geometric range from receiver antenna phase centre at reception time to satellite antenna phase centre at transmission time $(\mathrm{m}) . d t^{r}$ is receiver clock error $(\mathrm{s}), d t_{I G S}^{s}$ is the IGS satellite clock correction (s) and $T$ is tropospheric delay (m). $I_{1}, I_{2}, I_{5}$ are ionospheric delay on L1, L2, and L5 frequencies, respectively $(\mathrm{m}), d_{C 1}^{r}, d_{P 1}^{r}, d_{P 2}^{r}, d_{C 5}^{r}$ are receiver hardware delay for $\mathrm{C} 1, \mathrm{P} 1, \mathrm{P} 2$, and $\mathrm{C} 5$ pseudoranges, respectively (s), $\delta_{\Phi 1}^{r}, \delta_{\Phi 2}^{r}, \delta_{\Phi 5}^{r}$ are receiver hardware delay for $\Phi_{1}, \Phi_{2}$, and $\Phi_{5}$ carrier-phases, respectively (s), $\delta_{\Phi 1}^{s}, \delta_{\Phi 2}^{s}, \delta_{\Phi 5}^{s}$ are satellite hardware delay for $\Phi_{1}, \Phi_{2}$, and $\Phi_{5}$ carrier-phases, respectively (s) and $d_{P 1}^{s}, d_{P 2}^{s}$ are satellite hardware delay for P1 and P2 pseudoranges, respectively (s). $\lambda_{1}, \lambda_{2}, \lambda_{5}$ are carrier-phases wavelength for L1, L2, and L5, respectively (m), $N_{1}, N_{2}, N_{5}$ are integer ambiguity parameters for L1, L2, and L5, respectively, $e_{C 1}, e_{P 1}$, $e_{P 2}, e_{C 5}$ are un-modelled errors of $\mathrm{C} 1, \mathrm{P} 1, \mathrm{P} 2$, and $\mathrm{C} 5$ including orbital errors noise and multipath effect (m) and $\varepsilon_{\Phi 1}, \varepsilon_{\Phi 2}, \varepsilon_{\Phi 5}$ are un-modelled errors of $\Phi_{1}, \Phi_{2}$, and $\Phi_{5}$ including orbital errors, noise, and multipath effect $(\mathrm{m})$. 
3. P1-C5 DIFFERENTIAL CODE BIAS $\left(\mathrm{DCB}_{\mathrm{P} 1-\mathrm{C} 5}\right)$. To utilise the modernised C5 signal along with the existing GPS signals, the corresponding satellite hardware delay must be accurately determined. Typically, a geometry-free linear combination of P1 and P2 codes is used to estimate the ionospheric delay, while DCB is obtained as a by-product of the estimation process. Similar geometry-free linear combinations could be formed using L2C modernized signal to estimate C1-C2 differential code bias, $D C B_{C 1-C 2}^{s}$ (Elsobeiey and El-Rabbany, 2010). The same criteria could be applied for C1-C5 geometry-free combination to estimate $D C B_{P 1-C 5}^{s}$ as follows:

$$
\begin{gathered}
P_{4}=P_{1}-P_{2}=\xi I_{1}+c D C B_{P 1-P 2}^{r}+c D C B_{P 1-P 2}^{s}+\varepsilon_{P 4} \\
C_{4}=C_{1}-C_{5}=\xi^{\backslash} I_{1}+c D C B_{C 1-C 5}^{r}-c D C B_{P 1-C 1}^{s}+c D C B_{P 1-C 5}^{s}+\varepsilon_{C 4}
\end{gathered}
$$

where $P_{4}, C_{4}$ are geometry-free linear combination of $\mathrm{P} 1, \mathrm{P} 2$, and $\mathrm{C} 1, \mathrm{C} 5$, respectively (m), $I_{1}$ is the ionospheric delay of $\mathrm{L} 1(\mathrm{~m}), D C B_{C 1-C 5}^{r}$ is the receiver hardware delay difference of $\mathrm{C} 1$ and $\mathrm{C} 5$ observables (s) and $D C B_{P 1-P 2}^{r}$ is the receiver hardware delay difference of $\mathrm{P} 1$ and $\mathrm{P} 2$ observables (s). $\xi$ equals $-\left(f_{1}^{2}-f_{2}^{2}\right) / f_{2}^{2}, \xi^{\prime}$ equals $-\left(f_{1}^{2}-\right.$ $\left.f_{5}^{2}\right) / f_{5}^{2}$ and $\varepsilon_{P 4}, \varepsilon_{C 4}$ are $P_{4}$ and $C_{4}$ noise, respectively ( $\left.\mathrm{m}\right)$.

Ionospheric delay is usually estimated based on the Single-Layer Model (SLM). This model assumes that all free electrons are concentrated in a shell of infinitesimal thickness. The global Total Electron Content (TEC) model can be expressed as a spherical harmonic expansion which refers to a solar geomagnetic frame (Schaer et al., 1995) as follows:

$$
E(\beta, s)=\sum_{n=0}^{n_{\max }} \sum_{m=0}^{n} \tilde{P}_{n m}(\sin \beta)\left(a_{n m} \cos m s+b_{n m} \sin m s\right)
$$

where $\beta$ is the geographic latitude, $s$ is the sun-fixed longitude, $n_{\max }$ is the maximum degree of the spherical harmonic expansion, $\tilde{P}_{n m}=\Lambda(n, m) P_{n m}$ are the normalised associated Legendre functions of degree $n$ and order $m$, based on normalization function $\Lambda(n, m)$ and Legendre functions $P_{n m}$ and $a_{n m}, b_{n m}$ are the unknown TEC coefficients of the spherical harmonics, i.e., the global ionospheric model parameters to be estimated.

In order to estimate P1-C5 satellite differential code bias $\left(D C B_{P 1-C 5}^{S}\right)$, a cluster consisting of 60 IGS L5 tracking network stations was processed using Bernese GPS software (see Figure 1). 43 stations have X-tracking mode receivers and the remaining 17 stations have Q-tracking mode receivers. It is not clear whether or to what extent the estimated biases will depend on the signal component and tracking mode (Montenbruck et al., 2014), so in this research we assume that the effect of signal component and/or tracking mode is still at the uncertainty level of the estimated DCBs.

A session consisting of 60 days (DOY182-241, 2013) was chosen for processing the geometry-free linear combination P4 and C4 as in Equations (8) and (9), respectively. An elevation cut-off angle of $10^{\circ}$ was used. Slant TEC was reduced at any elevation angle (z) with the SLM mapping function $F(z)=1 / \cos \left(z^{\prime}\right)$ with $z^{\prime}=(R /(R+H)) \sin (z)$, setting the layer height $(\mathrm{H})$ to $450 \mathrm{~km}$ and the mean Earth radius $\mathrm{R}$ to $6371 \mathrm{~km}$. The maximum degree and order were set to 12 and 8, respectively. The period of validity of a single set of TEC parameters is 2 hours for all Global Ionospheric Maps (GIMs), that mean 12 sets of TEC parameters have to be estimated each day. 


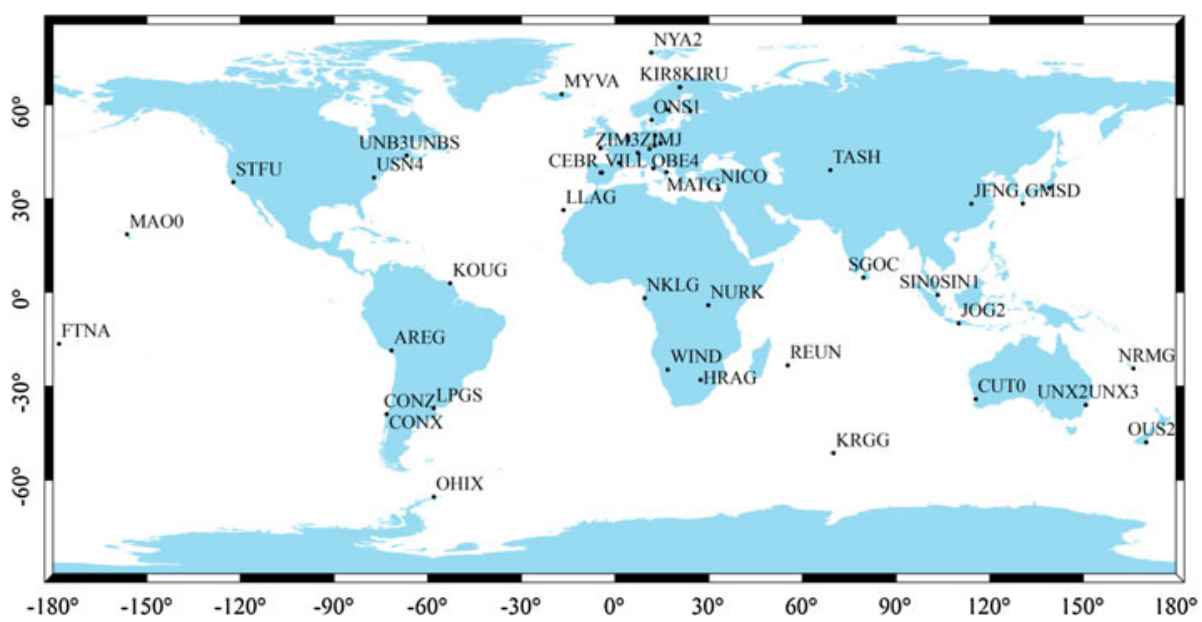

Figure 1. IGS Network used to estimate P1-C5 differential hardware delay.

Table 2. The estimated $D C B_{P 1-C 5}^{S}$ values and their corresponding RMS.

\begin{tabular}{lcccc}
\hline Satellite & $D C B_{P 1-C 5}^{s}(\mathrm{~ns})$ & $\mathrm{RMS}(\mathrm{ns})$ & $D C B_{P 1-P 2}^{s}(\mathrm{~ns})$ & $\mathrm{RMS}(\mathrm{ns})$ \\
\hline PRN25 & $-12 \cdot 502$ & $0 \cdot 120$ & $-7 \cdot 219$ & $0 \cdot 096$ \\
PRN01 & -4.915 & $0 \cdot 108$ & $-10 \cdot 651$ & 0.016 \\
PRN24 & -1.803 & $0 \cdot 110$ & -8.802 & $0 \cdot 076$ \\
PRN27 & -3.921 & $0 \cdot 101$ & $-6 \cdot 176$ & $0 \cdot 079$ \\
\hline
\end{tabular}

Because the DCB as well as the TEC estimates would be less accurate if a higher temporal resolution were assumed for DCB parameters, the satellite and station DCBs were represented by daily constants (Schaer et al., 1995). For datum definition, a zero-mean condition was imposed for satellites' DCBs (Dach et al., 2007).

For satellites broadcasting the modernised L5 signal, the only unknowns were $D C B_{P 1-C 5}^{s}$ along with the receiver differential code bias $\left(D C B_{C 1-C 5}^{r}\right)$ and the ionospheric delay term. For other satellites, the unknowns were $D C B_{P 1-P 2}^{S}$ along with the receiver differential code bias $\left(D C B_{P 1-P 2}^{r}\right)$ and the ionospheric delay term. Table 2 summarises the mean value of the estimated $D C B_{P 1-C 5}^{s}$ values and their corresponding root mean squares.

As can be seen in Table 2, satellite differential code bias for the modernised C5 signal $\left(D C B_{P 1-C 5}^{S}\right)$ are significant compared with the corresponding values of $D C B_{P 1-P 2}^{s}$ published by the IGS. The values of the Root Mean Square (RMS) of the estimated $D C B_{P 1-C 5}^{s}$ are relatively more than the corresponding values of $D C B_{P 1-P 2}^{s}$. This may be attributed, in part, to the limited number of stations tracking the modernised L5 signal compared with the number of stations tracking the legacy signals.

4. TRIPLE-FREQUENCY LINEAR COMBINATIONS. Typically, an ionosphere-free linear combination of code and carrier-phase observations is used in PPP to remove the first-order ionospheric effect (Zumberge et al., 1997). Wide-lane 
and narrow-lane combinations have been used to help in integer ambiguity resolution (Collins, 2008; Ge et al., 2008; Geng et al., 2012). The number of possible combinations is increased by the introduction of the third frequency, L5. However, there are different criteria to choose a specific combination from all possible combinations. A possible combination of interest is one that has a wide-lane wavelength or reduces the effect of the ionosphere compared to that on the L1 frequency. The derivation of triple-frequency linear combinations can be found in Cocard et al. (2008), Richert and El-Sheimy (2007) and Urquhart (2009). A simplified form of carrier-phase observation equation can be written as:

$$
\Phi_{n}=\rho^{\prime}+\lambda_{n} N_{n}-I_{n}
$$

where $\Phi_{n}$ is the carrier-phase observation on frequency $\mathrm{n}, \mathrm{n}=1,2,5, \rho$ ' represents the geometric range and includes satellite clock, tropospheric delay, and hardware delay terms $(\mathrm{m}), \lambda_{n}$ is carrier-phase wavelength $(\mathrm{m}), N_{n}$ is carrier-phase ambiguity and $I_{n}$ is the ionospheric delay term $(\mathrm{m})$.

Linear combination of the three carrier-phase observations (in units of metres) can be written as:

$$
\Phi_{C}=\alpha \Phi_{1}+\beta \Phi_{2}+\gamma \Phi_{5}
$$

where, $\alpha, \beta$, and $\gamma$ are the combination coefficients. This can be expanded to be:

$$
\Phi_{C}=(\alpha+\beta+\gamma) \rho^{\prime}+\alpha \lambda_{1} N_{1}+\beta \lambda_{2} N_{2}+\gamma \lambda_{5} N_{5}-\alpha I_{1}-\beta I_{2}-\gamma I_{5}
$$

Equation (13) shows that $(\alpha+\beta+\gamma)=1$ is a geometric constraint and the resultant combination will have $\lambda_{C}$ wavelength and integer ambiguity $N_{C}$ defined as follows:

$$
N_{C}=\frac{\alpha \lambda_{1} N_{1}+\beta \lambda_{2} N_{2}+\gamma \lambda_{5} N_{5}}{\lambda_{C}}, \lambda_{C}=\frac{\lambda_{1} \lambda_{2} \lambda_{5}}{i \lambda_{2} \lambda_{5}+j \lambda_{1} \lambda_{5}+k \lambda_{1} \lambda_{2}}
$$

According to Collins (1999), in order for $\mathrm{N}_{\mathrm{C}}$ to be an integer we can define the coefficient $\mathrm{i}, \mathrm{j}$, and $\mathrm{k}$ to be integers:

$$
i=\frac{\alpha \lambda_{1}}{\lambda_{C}}, j=\frac{\beta \lambda_{2}}{\lambda_{C}}, k=\frac{\gamma \lambda_{5}}{\lambda_{C}}
$$

The frequency of the combination can be written as:

$$
f_{C}=i f_{1}+j f_{2}+k f_{5}
$$

4.1. Combination's noise. Assuming there is no correlation between the three carrier-phases, the noise of the combined observable can be written as follows:

$$
\sigma_{C}=\sqrt{\alpha^{2} \sigma_{1}^{2}+\beta^{2} \sigma_{2}^{2}+\gamma^{2} \sigma_{5}^{2}}
$$

where $\sigma_{C}$ is the combination's noise (m) and $\sigma_{1}, \sigma_{2}, \sigma_{5}$ is the standard deviation of $\Phi_{1}$, $\Phi_{2}, \Phi_{5}$, respectively (m).

4.2. Combinations to reduce the ionospheric effect. Because of the dispersive nature of the ionosphere, it is possible to obtain combinations that completely 
Table 3. Triple-Frequency Linear Combinations.

\begin{tabular}{lccccr}
\hline Combination & $\alpha$ & $\beta$ & $\gamma$ & $\begin{array}{l}\text { Ionosphere } \\
\text { Amplification }\end{array}$ & $\begin{array}{l}\text { Noise } \\
\text { Amplification }\end{array}$ \\
\hline DUAL & $2 \cdot 5457$ & $-1 \cdot 5457$ & 0 & 0 & $3 \cdot 21$ \\
TRIPLE01 & $2 \cdot 2606$ & 0 & $-1 \cdot 2606$ & 0 & $2 \cdot 8214$ \\
TRIPLE02 & 0 & $12 \cdot 2553$ & $-11 \cdot 2553$ & 0 & $21 \cdot 42$ \\
TRIPLE03 & $2 \cdot 4504$ & $-1 \cdot 0282$ & $-0 \cdot 4222$ & $-0 \cdot 0001$ & $2 \cdot 8400$ \\
TRIPLE04 & $2 \cdot 2319$ & $0 \cdot 4348$ & $-1 \cdot 6667$ & $-0 \cdot 0408$ & $3 \cdot 2053$ \\
TRIPLE05 & $2 \cdot 2731$ & 0 & $-1 \cdot 2731$ & $-0 \cdot 0099$ & $2 \cdot 8413$ \\
TRIPLE06 & $2 \cdot 3158$ & $-0 \cdot 4511$ & $-0 \cdot 8647$ & $0 \cdot 0222$ & $2 \cdot 6531$ \\
TRIPLE07 & $2 \cdot 7018$ & $-2 \cdot 1053$ & $0 \cdot 4035$ & $-0 \cdot 0419$ & $3 \cdot 8589$ \\
TRIPLE08 & $2 \cdot 2871$ & $-0 \cdot 1485$ & $-1 \cdot 1386$ & $0 \cdot 0007$ & $2 \cdot 740$ \\
TRIPLE09 & $2 \cdot 2943$ & $-0 \cdot 2235$ & $-1 \cdot 0708$ & $0 \cdot 0060$ & $2 \cdot 71$ \\
\hline
\end{tabular}

eliminate the ionospheric delay. The ionospheric delay term in the triple-frequency combination can be written, from Equation (13), as:

$$
I_{C}=-\alpha I_{1}-\beta I_{2}-\gamma I_{5}
$$

In order to eliminate the effect of the ionospheric delay, the following condition must be satisfied:

$$
\alpha+\beta \frac{f_{1}^{2}}{f_{2}^{2}}+\gamma \frac{f_{1}^{2}}{f_{5}^{2}}=0
$$

This equation describes a surface of a plane which has infinite solutions. According to Richert and El-Sheimy (2007)), any values of $\alpha, \beta$, and $\gamma$ that lie on this plane will produce an ionosphere-free combination. The closer the values of $\alpha, \beta$, and $\gamma$ to the plane, the smaller the ionosphere amplification factor. Table 3 summarises coefficients of the chosen triple-frequency combinations that eliminate or reduce the ionospheric effect and the corresponding resultant noise amplification factors.

5. TEST RESULTS USING DIFFERENT LINEAR COMBINATIONS. To test the effect of these triple-frequency combinations on the PPP solution and convergence time, GPS data from ten randomly selected globally distributed MGEX stations, namely HARB, KOUR, KZN2, MAS1, NNOR, REYK, RIO2, THTG, UNBD, and WUH2, were processed (Figure 2) using the PPP software developed in Elsobeiey (2012). The input data was the pseudorange and carrier-phase measurements (Equations (1) to (7)) linearly combined according to Table 3 as follows:

$$
\begin{gathered}
P_{C}=\rho+c\left(d t^{r}-d t_{I G S}^{s}\right)+T+I_{C}+b_{C}^{r}+b_{C}^{s}+e_{C} \\
\Phi_{C}=\rho+c\left(d t^{r}-d t_{I G S}^{s}\right)+T+I_{C}+b_{\Phi C}^{r}+\lambda_{C} N_{C}+\varepsilon_{C}
\end{gathered}
$$




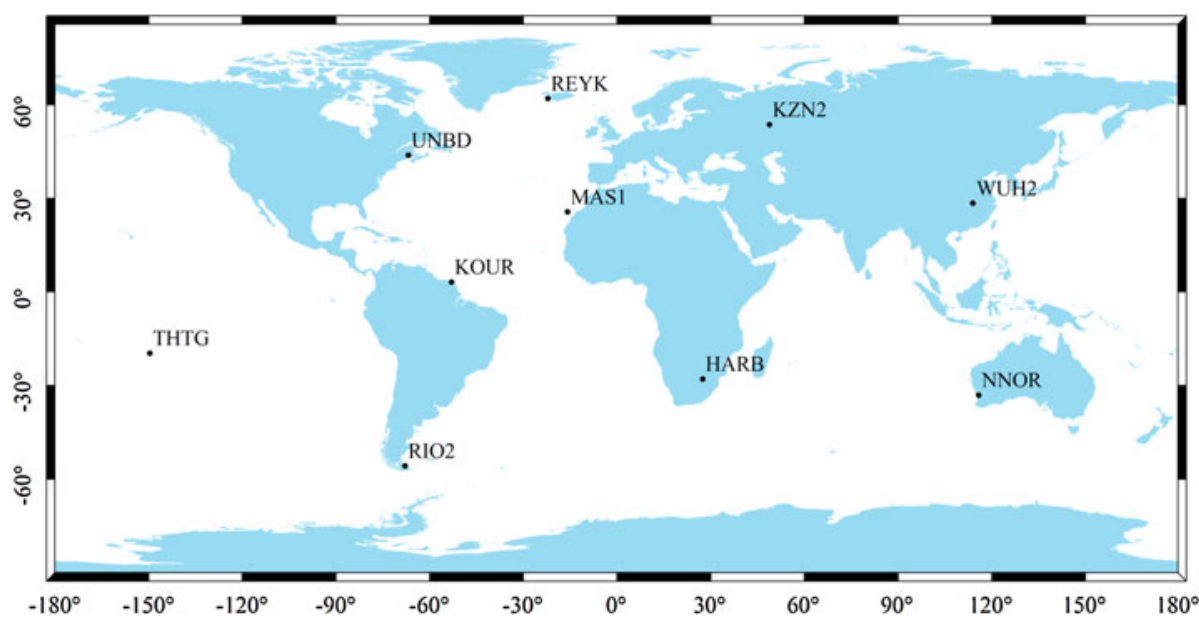

Figure 2. MGEX Network used to test PPP triple-frequency combinations.

where

$$
\begin{gathered}
I_{C}=\alpha I_{1}+\beta I_{2}+\gamma I_{5} \\
b_{C}^{r}=c\left(\alpha d_{P 1}^{r}+\beta d_{P 2}^{r}+\gamma d_{C 5}^{r}\right) \\
b_{C}^{s}=-c\left[\alpha\left(D C B_{P 1-C 1}^{s}-\xi_{1} D C B_{P 1-P 2}^{s}\right)+\beta\left(\xi_{2} D C B_{P 1-P 2}^{s}\right)+\gamma\left(D C B_{P 1-C 5}^{s}-\xi_{1} D C B_{P 1-P 2}^{s}\right)\right] \\
b_{\Phi C}^{r}=c\left[\alpha \delta_{\Phi 1}^{r}+\beta \delta_{\Phi 2}^{r}+\gamma \delta_{\Phi 5}^{r}\right] \\
\lambda_{C}=\frac{\lambda_{1} \lambda_{2} \lambda_{5}}{i \lambda_{2} \lambda_{5}+j \lambda_{1} \lambda_{5}+k \lambda_{1} \lambda_{2}} \\
N_{C}=\frac{c}{\lambda_{C}}\left[\alpha\left(\delta_{\Phi 1}^{s}-\xi_{1} d_{P 1}^{s}+\xi_{2} d_{P 2}^{s}\right)+\beta\left(\delta_{\Phi 2}^{s}-\xi_{1} d_{P 1}^{s}+\xi_{2} d_{P 2}^{s}\right)+\gamma\left(\delta_{\Phi 5}^{s}-\xi_{1} d_{P 1}^{s}+\xi_{2} d_{P 2}^{s}\right)\right] \\
+\alpha N_{1}+\beta N_{2}+\gamma N_{5}
\end{gathered}
$$

$b_{C}^{r}$ is receiver hardware delay combination $(\mathrm{m}), b_{C}^{s}$ is satellite hardware delay combination $(\mathrm{m}), e_{C}$ is pseudorange combination noise $(\mathrm{m})$ and $\varepsilon_{C}$ is carrier-phase combination noise $(\mathrm{m})$.

An IGS precise orbit was used for satellite coordinates. IGS precise clock corrections were also applied. Tropospheric corrections were accounted for using the Hopfield model (Hopfield, 1969) and global mapping function was used for mapping the zenith tropospheric delays (wet and dry) to each satellite-specific elevation angle. All remaining errors, including carrier-phase windup, relativity, sagnac effect, Earth tides, and ocean loading were accounted for with sufficient accuracy using existing models (Kouba, 2009). Figures 3 through 8 show the position errors (Latitude, Longitude and Height) for NNOR and UNBD stations compared with the IGS published coordinates, as examples.

As can be seen in Figures 3 to 8, TRIPLE07 combination is the most efficient PPP model. TRIPLE07 has the combination [2.7018, -2.1053, 0.4035] and ionosphere amplification factor of -0.0419 while the noise amplification factor is $3 \cdot 85$. The second combination is the dual frequency ionosphere-free L1, L2 combination, DUAL 


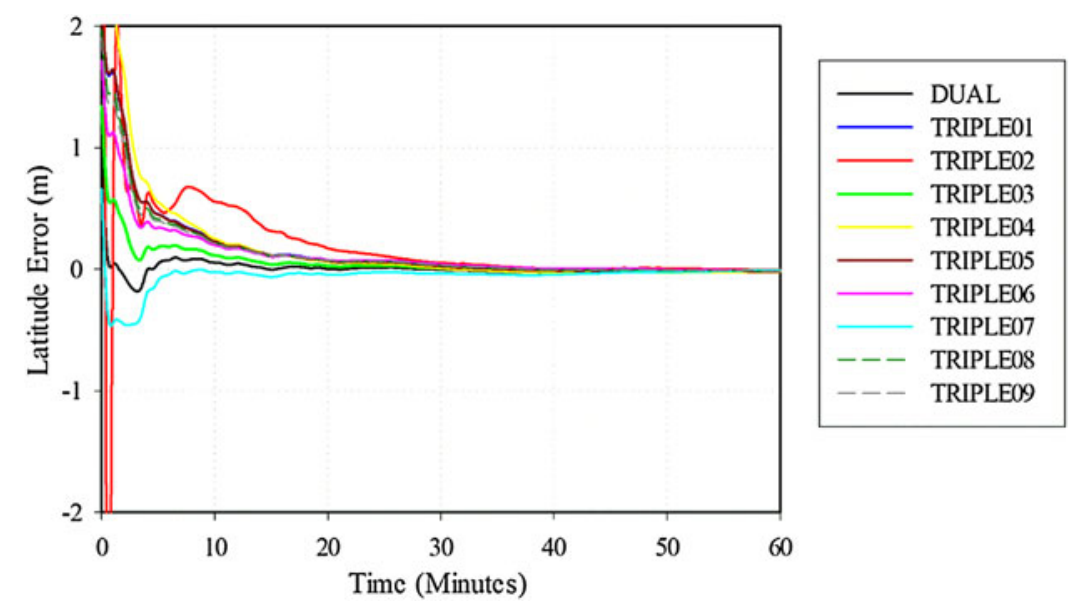

Figure 3. Latitude errors from various triple-frequency combinations at NNOR Station, DOY200, 2013.

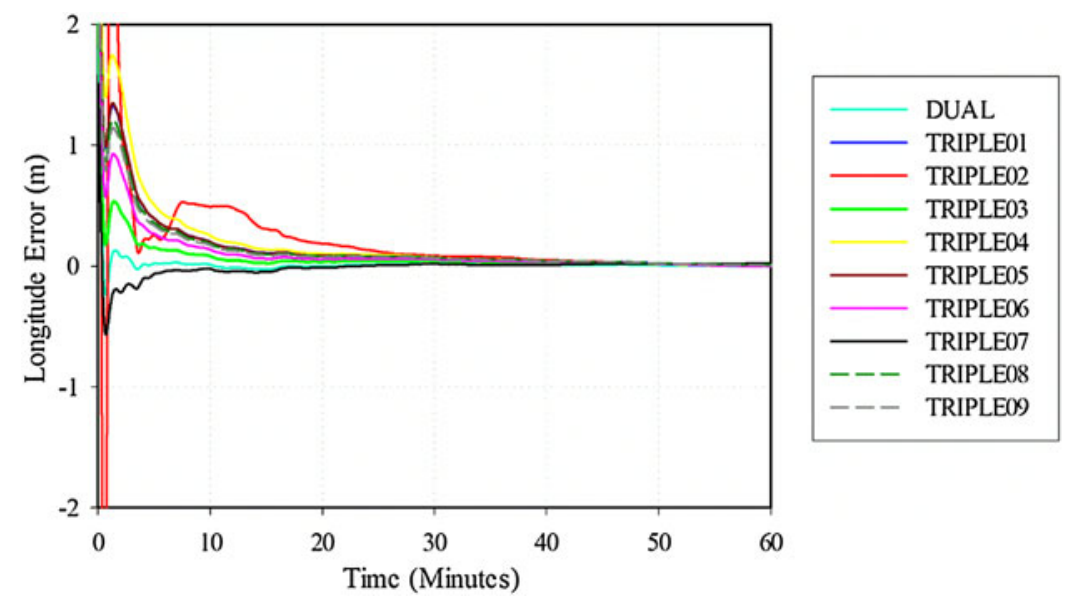

Figure 4. Longitude errors from various triple-frequency combinations at NNOR Station, DOY200, 2013.

$[2 \cdot 5457,-1 \cdot 5457,0]$. The dual frequency ionosphere-free linear combination has a noise amplification factor of $3 \cdot 21$. The third combination is TRIPLE03 [2.4504, $-1.0282,-0.4222]$, which has an ionosphere amplification factor of -0.0001 and noise amplification factor of $2 \cdot 84$. The fourth triple-frequency combination is TRIPLE06 [2.3158, $-0.4511,-0.8647]$ with ionosphere amplification factor of 0.0222 and noise amplification factor of 2.6531 . The worst combination is the L2 and L5 ionosphere-free linear combination, TRIPLE01 [0, 2.2606, -1.2606], because of the noise amplification factor $21 \cdot 42$. Table 4 shows the average RMS of 


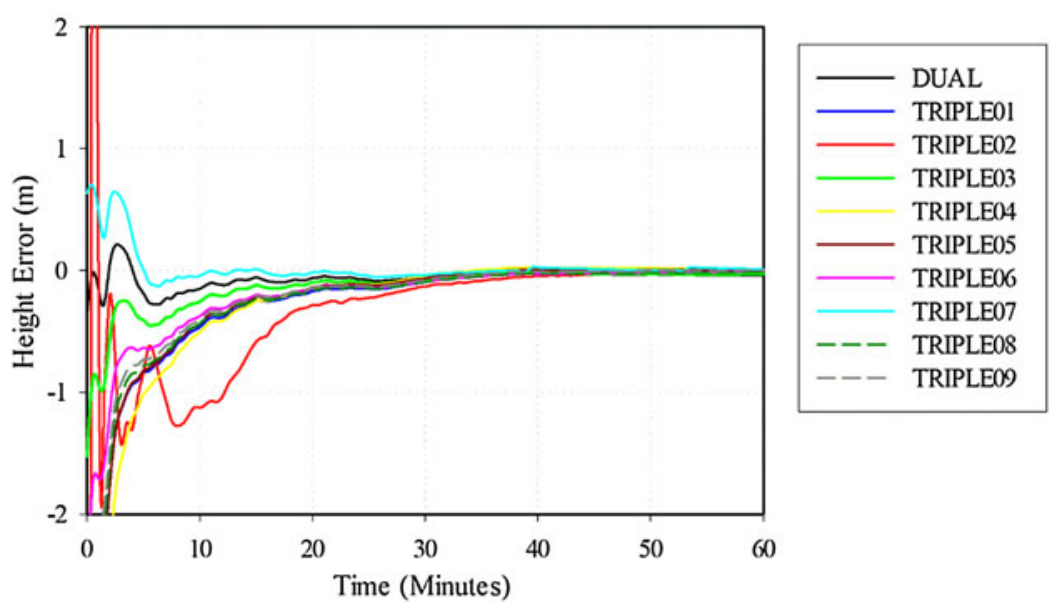

Figure 5. Height errors from various triple-frequency combinations at NNOR Station, DOY200, 2013.

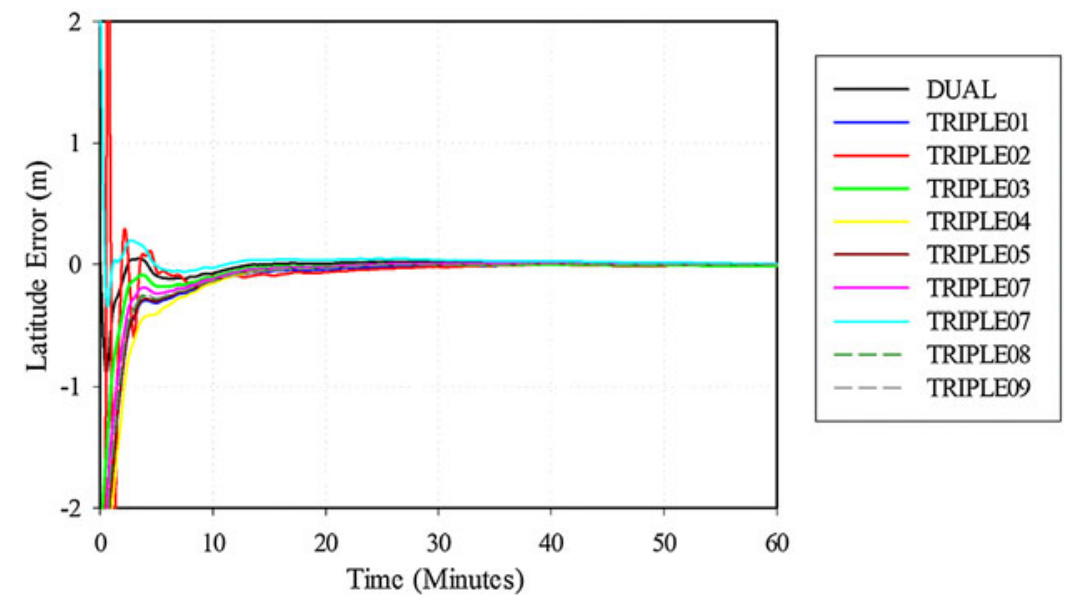

Figure 6. Latitude errors from various triple-frequency combinations at UNBD Station, DOY200, 2013.

the estimated coordinates of the best triple-frequency combinations compared with the dual frequency combination.

As can be seen in Table 4, the RMS of the estimated coordinates of TRIPLE07 is better than the corresponding values of the dual-frequency linear combination (DUAL). The same conclusion can be obtained from Figures 3 to 8 . It should be pointed out here that a maximum of two modernised Block IIF satellites are available in the user's sky most of the time. Better results are expected to be obtained as the modernisation program progresses. In addition, Figures 3 to 8 show that the convergence time using the TRIPLE07 combination is smaller than the convergence time obtained 


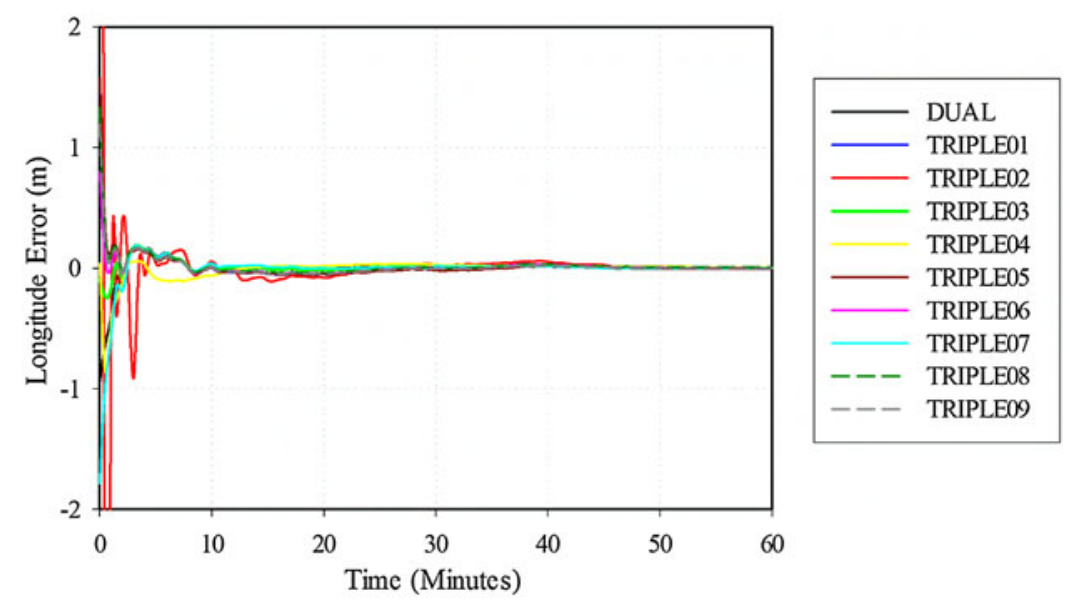

Figure 7. Longitude errors from various triple-frequency combinations at UNBD Station, DOY200, 2013.

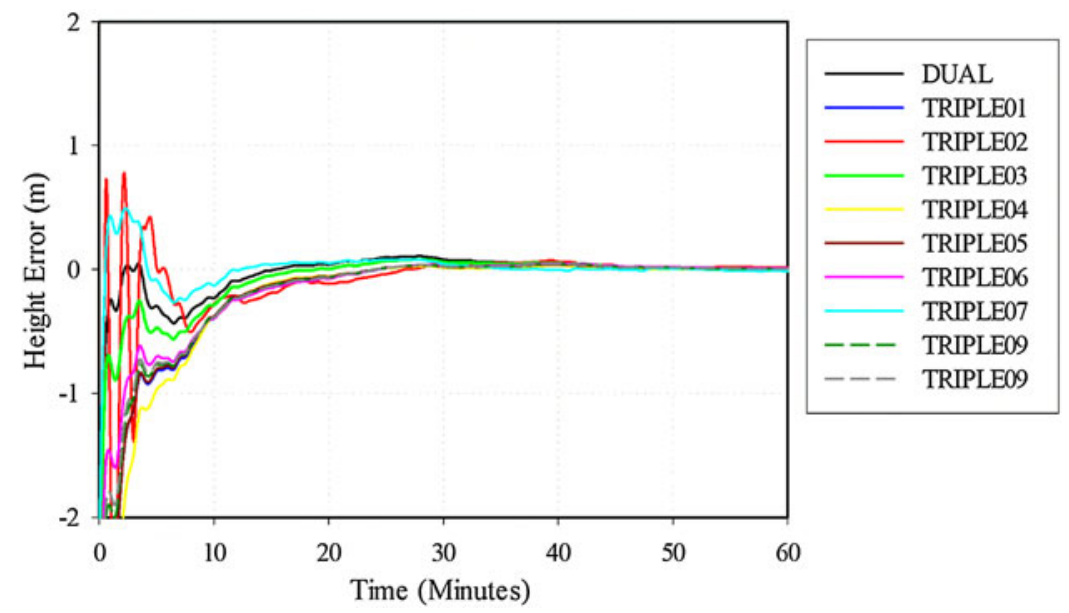

Figure 8. Height errors from various triple-frequency combinations at UNBD Station, DOY200, 2013.

Table 4. Root Mean Square (RMS) of the Estimated Coordinates.

\begin{tabular}{lccc}
\hline & \multicolumn{2}{c}{ Coordinates RMS (m) } \\
\cline { 2 - 4 } Combination & Latitude & Longitude & Height \\
\hline DUAL & $0 \cdot 0347$ & $0 \cdot 054$ & $0 \cdot 073$ \\
TRIPLE07 & $0 \cdot 0281$ & $0 \cdot 020$ & $0 \cdot 043$ \\
TRIPLE03 & $0 \cdot 041$ & $0 \cdot 056$ & $0 \cdot 107$ \\
TRIPLE06 & $0 \cdot 053$ & $0 \cdot 061$ & $0 \cdot 132$ \\
\hline
\end{tabular}


from the dual-frequency linear combination. The average time required for the solution to be converged using triple-frequency is about $10 \%$ less than the average time of the dual-frequency linear combination.

6. CONCLUSIONS. To fully explore the modernised L5 signal, P1-C5 differential code bias must be determined. In this paper, the global network of MGEX stations was used to estimate P1-C5 satellites differential code biases $\left(D C B_{P 1-C 5}^{S}\right)$. Mathematical background for triple-frequency linear combinations was provided along with the resultant noise and ionosphere amplification factors. Nine triple-frequency linear combinations were chosen for processing the modernised L5 signal along with the legacy GPS signals. Finally, test results using real GPS data from several MGEX stations were provided showing the benefits of the availability of the third frequency on PPP solution conversion time and the precision of the estimated parameters. It was shown that triple-frequency combinations can improve the PPP conversion time and the precision of the estimated coordinates by about $10 \%$. These results are considered promising for using the modernised GPS signals for precise positioning applications especially when the fully modernised GPS constellation is available.

\section{ACKNOWLEDGMENTS}

This work was funded by the Deanship of Scientific Research (DSR), King Abdulaziz University, Jeddah, under grant No. 150-007-D1434. The Author, therefore, acknowledges with thanks DSR technical and financial support. The data sets used in this research were obtained from the IGS Multi-GNSS Experiment (MGEX) website http://igs.org/mgex.

\section{REFERENCES}

Cocard, M., Bourgon, S., Kamali, O. and Collins, P. (2008). A systematic investigation of optimal carrierphase combinations for modernized triple-frequency GPS. Journal of Geodesy, 82, 555-564.

Collins, P. (1999). An overview of GPS inter-frequency carrier phase combinations. Geodetic Survey Division, Technical Memorandum. University of New Brunswick (UNB), New Brunswick.

Collins, P. (2008). Isolating and Estimating Undifferenced GPS Integer Ambiguities, Proceedings of the 2008 National Technical Meeting of The Institute of Navigation, San Diego, CA, 720-732.

Dach, R., Hugentobler, U., Fridez, P. and Meindl, M. (2007). Bernese GPS Software, Version 5.0. Astronomical Institute, University of Bern, 2007.

Elsobeiey, M. and El-Rabbany, A. (2010). On stochastic modeling of the modernized global positioning system (GPS) L2C signal. Measurement Science and Technology, 21, 055105.

Elsobeiey, M. (2012). An Improved Model for Precise Point Positioning with Modernized Global Positioning System, Ph.D. thesis, Department of Civil Engineering. Ryerson University, Toronto, Canada.

Elsobeiey, M. and El-Rabbany, A. (2013). Rigorous Analysis of Modernized GPS C5 Differential Hardware Delay. The 2013 Canadian Institute of Geomatics Annual Conference and the 2013 International Conference on Earth Observation for Global Changes (EOGC'2013), Toronto, Ontario, Canada, 159-162.

Ge, M., Gendt, G., Rothacher, M., Shi, C. and Liu, J. (2008). Resolution of GPS carrier-phase ambiguities in Precise Point Positioning (PPP) with daily observations. Journal of Geodesy, 82, 389-399.

Geng, J. and Bock, Y. (2013). Triple-frequency GPS precise point positioning with rapid ambiguity resolution. Journal of Geodesy, 87, 449-460.

Geng, J., Shi, C., Ge, M., Dodson, A., Lou, Y., Zhao, Q. and Liu, J. (2012). Improving the estimation of fractional-cycle biases for ambiguity resolution in precise point positioning. Journal of Geodesy, 86, 579-589.

Hofmann-Wellenhof, B., Lichtenegger, H. and Wasle, E. (2008). GNSS-global navigation satellite systems: GPS, GLONASS, Galileo, and more. Springer, Wien; New York. 
Hopfield, H.S. (1969). Two-quartic tropospheric refractivity profile for correcting satellite data. Journal of Geophysical Research, 74, 4487-4499.

Kouba, J. (2009). A guide to using International GNSS Service (IGS) products. Available online at http://igscb.jpl.nasa.gov/igscb/resource/pubs/GuidetoUsingIGSProducts.pdf, accessed on 17 Nov, 2013.

Leick, A. (2004). GPS satellite surveying, 3rd ed. John Wiley, Hoboken, NJ.

Montenbruck, O., Hauschild, A. and Steigenberger, P. (2014). Differential Code Bias Estimation Using Multi-GNSS Observations and Global Ionosphere Maps. Proceedings of the 2014 International Technical Meeting of The Institute of Navigation, San Diego, California, January 2014, 802-812.

Richert, T. and El-Sheimy, N. (2007). Optimal linear combinations of triple frequency carrier phase data from future global navigation satellite systems. GPS Solutions, 11, 11-19.

Schaer, S. (1999). Mapping and predicting the Earth's ionosphere using the global positioning system. $\mathrm{PhD}$ Thesis, University of Berne, Switzerland.

Schaer, S., Beutler, G., Mervart, L. and Rothacher, M. (1995). Global and Regional Ionosphere Models Using The GPS Double Difference Phase Observable. Proceedings of the IGS Workshop on Special Topics and New Directions, edited by G. Gendt and G. Dick, 77-92, GFZ, Potsdam, Germany, May 15-18, 1995.

Urquhart, L. (2009). An Analysis of Multi-Frequency Carrier Phase Linear Combinations for GNSS. Senior technical report, Department of Geodesy and Geomatics Engineering Technical Report No. 263, University of New Brunswick, Fredericton, New Brunswick, Canada, p. 71.

USNO. (2013). United States Naval Observatory. Retrieved September 15, 2013 from http://www.usno.navy. $\mathrm{mil} / \mathrm{USNO} /$ time/gps/current-gpsconstellation.

Wang, Z., Wu, Y., Zhang, K. and Meng, Y. (2005). Triple-frequency method for high-order ionospheric refractive error modelling in GPS modernization. Journal of Global Positioning Systems, 4, 291-295.

Zumberge, J.F., Heflin, M.B., Jefferson, D.C., Watkins, M.M. and Webb, F.H. (1997). Precise point positioning for the efficient and robust analysis of GPS data from large networks. Journal of Geophysical Research: Solid Earth, 102, 5005-5017. 